\title{
A Second Best Theory of Institutional Quality
}

\section{Cristina Molinari}

(C) Springer Science+Business Media New York 2013

\begin{abstract}
This paper illustrates a theory of the second best where the constraints to the achievement of the optimum are of institutional nature. We consider the effects of corruption and bad governance on the public decision to privatize the provision of a service when contracts are incomplete and there is asymmetric information. We show that both corruption and bad governance are detrimental to welfare, but that removing only one of the two is not necessarily beneficial if the other is still present. The theory supplies a possible explanation to the controversial empirical evidence on the economic effects of corruption.
\end{abstract}

Keywords Corruption · Governance $\cdot$ Positive selection · Privatization · Second best

\section{Introduction}

The theory of the second best states that if we are away from the optimal conditions on more than one dimension, getting closer to some, but not all of them, is not necessarily beneficial. More formally, in the presence of constraints that prevent the attainment of the optimum, satisfying a larger number of optimization conditions is not guaranteed to be superior to a situation in which fewer requirements are fulfilled. This principle, originally formalized by Lipsey and Lancaster (1956), is now a standard chapter in most public economics textbooks. (See, for example, Laffont 1988). Recent surveys of its impact on economic theory are Boadway (1997) and Lipsey (2007).

M. C. Molinari $(\bowtie)$

Department of Economics, Università Ca’ Foscari Venezia, San Giobbe 873, 30121 Venice, Italy e-mail: cmolinar@unive.it 
The theory has been applied to many situations where the constraints to the achievement of the first best were of economic nature. ${ }^{1}$ This paper investigates an organizational version of the principle in which the nature of the constraints is institutional. In particular, we consider two deficiencies of the institutional quality of a nation which interfere with the public decision process: the presence of corruption and the lack of an adequate system of public governance. Extending the theory of the second best, we show that when these imperfections co-exist, removing only one of the two does not necessarily improve social welfare: a system characterized by bad governance is not necessarily working better if we remove corruption and, conversely, the functioning of a system characterized by corruption is not always enhanced by an improvement in the quality of its governance. This result implies that policy recommendations cannot be easily formulated on the basis of first-best prescriptions.

The motivation for this paper comes from the empirical literature on corruption. Although corruption is often associated to poor economic performance, empirical studies are not conclusive: cross-country analyses do not find a robust link between corruption and growth (Svensson 2005) and the so-called East-Asian paradox (Rock and Bonnett 2004; Vial and Hanoteau 2010) shows that there are countries, such as China and Indonesia, that represent blatant exceptions to the principle that corruption hampers growth.

Our results offer a possible explanation for such conflicting evidence. If the economic effects produced by corruption depend on the existence of other institutional distortions, studying the relationship between the level of corruption and the economic performance of countries cannot abstract from their overall institutional setting. In other words, the association of corruption with poor economic performance may hold on average, but corruption could still have expansionary economic effects on a subset of nations. In particular, it could be beneficial in countries where governance is defective, because it might help overcome the distortions caused by ill-functioning institutions.

To investigate this possibility we start from a standard model of the relative merits of public vs. private provision of a service which is based on a publicly owned facility (e.g., a school or a prison). We consider the choice between provision in house, when the facility is used by a public employee to deliver the service, and outsourcing to a private firm, accompanied by the privatization of the asset.

To account for the benefits and the costs of each choice, we assume that the provider of the service-either the public manager or the private contractor-can spend effort in introducing innovations. The welfare effect of innovations is twofold: on the one hand, they decrease the cost of the service; on the other hand, they have an adverse effect on its quality. The net result, therefore, depends on the magnitude of the social cost of the reduced quality and on the manager's cost cutting efficiency. The latter varies across providers and it is their private information. Effort is not contractible and the final approval on the decision to innovate lies with the owner of the facility. Therefore, the choice on the form of provision, through the allocation of the

\footnotetext{
${ }^{1}$ A list of economic applications can be found in the original Lispey and Lancaster's article.
} 
residual rights of control, determines the incentives to introduce innovations and, ultimately, social welfare. For example, a private provider tends to innovate more than a public manager because he is after cost reductions, regardless of their social cost due to degraded quality.

We assume that the Government asks the private provider to pay a take-it-or leave-it price for the facility. If the private contractor accepts the contract, provision is private; otherwise, it is public. Because managers are heterogenous in their capacity to pursue efficiency, setting a privatization price induces a selection on the ability of the managers and, thus, has an impact on welfare. Therefore, the price chosen affects the final outcome in two ways: it determines whether provision is private or public (and thus determines the incentives to innovate), but it also operates a selection on the type of manager. Thus, the welfare effects of the decision on the form of provision are subsumed by the privatization price set by the Government.

Our institutional version of the second best theory confronts two types of institutional shortcomings in this benchmark setting. The first is corruption. Its role, as it is standard in the literature, is to change the objective function of the Government: instead of maximizing social welfare, a dishonest public official maximizes the kickbacks he can get. The second is the lack of a satisfactory system of public governance, an element which is more difficult to capture because there is no univocal notion of what bad governance is; for example, for some authors corruption is one of the many forms that bad governance takes. In this paper, however, while corruption is related to the decision maker's selfishness, governance has to do with the way the decision process works and with the capacity of the governing body to formulate good policies and implement them. One major ingredient to complete this task, in today's complex organizations, is the ability to gather the information that is usually dispersed among many actors of the front-line staff and move it upwards to the final decision maker. This is why we choose to equate good governance with the decision maker's access to reliable information.

The existence of these two shortcomings, corruption and bad governance, interferes with the optimal way to fix the privatization price. The first best price, in fact, should be optimally set at a higher level when the social cost of innovation is greater. Doing so produces two results: on the one hand, privatization, and its associated overincentive to innovate, becomes less likely when it is socially more damaging and, on the other hand, the social cost of privatizing is partially compensated by selecting higher ability private managers exactly when private provision is socially less desirable. However, both corruption and bad governance fall short of this benchmark. This is so because the social cost plays no role in the objectives of a dishonest decision maker and, therefore, the transfer he asks (in the form of a bribe instead of a privatization price) is independent of it. Moreover, an honest decision maker, when operating in a system characterized by bad governance, cannot set the price at its first best level because it does not have the necessary information. The fact that both distortions, taken alone, are detrimental to social welfare, however, does not imply that having less of one of them, while the other is still present, is necessarily beneficial. This paper uncovers how the two institutional faults interact in determining the privatization price so that a second best theorem is obtained. 
The remainder of the paper is structured as follows. A brief review of the literature is contained in "Related Literature". We next present a simple theoretical framework of the tradeoff between public and private provision with symmetric information given in "A Benchmark Model of Public vs. Private Provision". This model is then developed in "Asymmetric Information and the Selection Effect of Prices" with the introduction of asymmetric information and the analysis of the selection properties of the privatization price. Our institutional version of the second best theory and its policy implications are found in "Institutions and the Second Best". Finally, a summary of the main findings is found in "Conclusion".

\section{Related Literature}

This paper combines in a novel way various ideas already present in the literature. Given the virtual explosion of research on the economics of corruption in the last twenty years, we do not aim at giving a comprehensive literature review and we limit our attention to works where some of these ideas are present. General surveys are Bardhan (1997) and Aidt (2003).

The first idea that this paper revisits is efficient corruption, i.e. the conclusion that having less corruption is not necessarily welfare improving (e.g., Lui 1985; Beck and Maher 1986). However, in our paper corruption is not beneficial in itself: we simply argue that it could be, if combined with other institutional failures.

A second theme of this paper is the importance of the interplay between corruption and institutions. This idea is at the center of some dynamic growth models. Blackburn and Forgues-Puccio (2009) and Ehrlich and Lui (1999) show that the form of government organization-centralized or decentralized-determines the level of corruption and, thus, the rate of growth. A similar mechanism is at play in Aidt et al. (2008) who argue that political accountability is negatively correlated to corruption which, in turn, adversely affects growth. In all of these papers, however, the negative relationship between corruption and growth is postulated and the effect of institutions on welfare is mediated through their effect on the endogenous level of corruption. A partial exception to this approach is de Vaal and Ebben (2011); in their paper corruption is exogenous and, alongside the usually negative effect of corruption on growth, there is also a possible indirect effect on political stability which, in turn, enhances production. The sign of this second effect depends on the quality of the institutional environment; thus, the net result of corruption on the growth rate ends up being regime specific. Our approach, however, is different because we do not assume a negative (or positive) relationship between corruption and welfare. We posit that corruption is just a transfer payment; as such, it is not bad (or good) for itself and the sign of its effect on welfare is endogenously determined through the selection operated by the privatization price.

Finally, there is a growing empirical literature on how institutions affect the economic consequences of corruption. These papers differ in the variable they use to measure the quality of governance. For example, Aidt et al. (2008) look at the accountability of politicians, $\mathrm{Li}$ and $\mathrm{Wu}$ (2010) use the lack of trust in the society, Méndez and Sepùlveda (2006) and Heckelman and Powell (2010) look at the role of 
political or economic freedom, respectively. Other papers use indexes of the institutional setting based on more than one variable. For example, Mèon and Weill (2010) adopt an index which includes, among others, quantitative measures of the quality of the bureaucracy, the independence of the civil servants from political pressure and the incidence of regulations hindering market performance; de Vaal and Ebben (2011) consider institutional features of the country such as political stability, property rights, and the political system; and Mèon and Sekkat (2005) look at the quality of political institutions measured by variables such as voice and accountability, lack of political violence, regulatory burden. Most of the evidence offered in these papers indicates, as suggested by this paper, that the interdependence between corruption and the way institutions work is an important element not to be dismissed, although there are considerable data challenges when measuring a multifaceted notion such as the quality of institutional governance.

\section{A Benchmark Model of Public vs. Private Provision}

This section introduces a simple benchmark model of the trade-offs between public and private provision of goods such as hospital, school or prison services. The model is a special version of Hart et al. (1997) to which we refer for detailed proofs and motivation. ${ }^{2}$

A facility (for example a school) is necessary to provide a service. The basic version of the service costs $C_{0}$ and brings net social welfare $W_{0}$, but the manager of the facility can modify it by spending effort $e$ in innovations. The latter have both positive and negative effects on welfare: on the one hand, they reduce production costs by $\sigma \sqrt{e}$, where $\sigma \in[0,1]$ is a measure of the manager's cost reduction ability; but, on the other hand, they decrease the quality of the service and, thus, its social benefit by $\delta e, \delta \in[0,1]$. Moreover, the manager's private cost of effort is $e$. Overall, the modified version of the service produces net social welfare

$$
W=W_{0}+\sigma \sqrt{e}-\delta e-e .
$$

Notice that higher effort is not necessarily desirable in this model and its net effect depends on the parameters $\sigma$ and $\delta$.

As it is usually the case, the manager's effort is not verifiable; consequently, it cannot be contractually specified ex-ante, i.e. contracts are incomplete. This makes the allocation of residual control rights on the facility paramount. Private and public provision differ exactly in how they assign such residual control rights. What follows illustrates these differences and investigates how they affect equilibrium effort.

\section{Private Provision}

When provision is private, the manager can introduce any innovation without Government's approval. A very natural situation in which this occurs is when the facility

\footnotetext{
${ }^{2}$ In particular, we consider the case $b(e)=\delta e, c(e)=\sigma \sqrt{e}, \beta=0, \lambda=1$.
} 
(jail, school, etc.) is privatized and it is sold to a private firm that uses it to provide the service. For convenience, this is the setting we refer to in what follows. However, there are circumstances other than privatization in which our definition of private provision applies: the notion of facility could be broadly interpreted as any input, sold by the Government to a private provider, that is necessary to supply the service, e.g., a permit or a license. All is needed for the model to apply to this more general setting is that the Government cannot set effort $e$ when it outsources the provision of the service and that the provider is a monopolist.

Private provision of the good is based on a long-term contract between the Government and a risk neutral private manager specifying two prices, one for the facility and the other for the basic version of the service, respectively denoted by $P_{F}$ and $P_{0}$. Suppose that the price of the basic version exactly covers the cost, i.e. $P_{0}=C_{0}$, and $P_{F}$ is small enough that the private manager is willing to enter the contract.

Given the allocation of the residual control rights, the private manager chooses effort in order to maximize $\sigma \sqrt{e}-e$. Then, under private provision the equilibrium effort, denoted by $e_{P}$, is

$$
e_{P}=\frac{\sigma^{2}}{4}
$$

and equilibrium welfare as a function of $\sigma^{2}$ is

$$
W_{P}\left(\sigma^{2}\right)=W_{0}+\frac{\sigma^{2}}{4}(1-\delta) \text {. }
$$

\section{Public Provision}

Consider now public provision. Assume that residual control rights are shared by the public employee and the Government: the public employee cannot implement cost reductions without Government approval but, on the other hand, the cost reducing effort is embodied in the public employee's human capital, so the Government cannot achieve cost reductions without the employee's participation.

A risk neutral public employee initially signs a contract with the Government for the provision of the basic version of the service, where $P_{0}$ is now interpreted as the wage the employee receives for providing the basic version (as before, $P_{0}=C_{0}$ ). Cost reduction innovations can be introduced by renegotiating this initial contract. Assume that gains are split according to the Nash bargaining solution ${ }^{3}$ where, in the absence of an agreement, only the basic good is produced. Therefore, the employee's payoff after renegotiation is given by $\frac{1}{2}(\sigma \sqrt{e}-\delta e)-e$.

It follows that under public provision equilibrium effort, denoted by $e_{G}$, is

$$
e_{G}=\frac{\sigma^{2}}{4(2+\delta)^{2}}
$$

\footnotetext{
${ }^{3}$ Any asymmetric division where the public employee receives a share $\alpha$ of the gains will lead to the same qualitative results as long as $0<\alpha<1$.
} 
and equilibrium social welfare is

$$
W_{G}\left(\sigma^{2}\right)=W_{0}+\frac{\sigma^{2}}{4} \frac{\delta+3}{(2+\delta)^{2}} .
$$

\section{Evaluation of Ownership Structure}

To evaluate the efficiency of the two forms of provision, compare the two equilibrium efforts $e_{P}$ of Eq. 1 and $e_{G}$ of Eq. 2 with the first best effort $e^{*}$ that maximizes social welfare $W_{0}+\sigma \sqrt{e}-\delta e-e$. Since

$$
e^{*}=\frac{\sigma^{2}}{4(\delta+1)^{2}},
$$

neither form of provision is first-best efficient as $e_{G}<e^{*}<e_{P}$. In particular, $e^{*}<$ $e_{P}$ because private provision gives too strong incentives to introduce cost-reducing innovations. A private manager does not care about the negative externality that his effort has on social welfare; thus, his cost reducing effort is greater than the socially optimal one. On the other hand, $e_{G}<e^{*}$, i.e. the cost reducing effort under public provision is smaller than the first best effort, because a public manager gains only half of the benefits associated to his effort but bears the whole cost; therefore, he has too little incentives to introduce cost reducing innovations.

When the private and public managers are equally efficient, which form of provision is second-best efficient depends on the value of the social costs of the cost reducing effort $\delta$. The equation $W_{P}(\sigma)=W_{G}(\sigma)$ determines a threshold value $\bar{\delta}=\sqrt{2}-1 \simeq 0.4142$ such that private provision is better than public if (and only if) $\delta<\bar{\delta}$. In other words, when the two managers have the same cost reducing efficiency $\sigma$, private provision is preferable if the social cost of effort, which is disregarded by a private manager, is not too large.

If, instead, the private and the public manager have different efficiencies in cost reductions, denoted respectively with $\sigma_{P}$ and $\sigma_{G},{ }^{4}$ private provision is better than public if

$$
\sigma_{P}^{2}>\frac{(\delta+3)}{(1-\delta)(2+\delta)^{2}} \sigma_{G}^{2} .
$$

Since the expression on the right is increasing in $\delta$, as $\delta$ gets larger the private manager needs higher and higher efficiency, compared to the public employee, in order to compensate for the negative externality of the cost reduction.

\footnotetext{
${ }^{4}$ As shown later, even if the private and public manager are ex-ante identical in terms of cost-reducing efficiency, the choice of provision might lead to endogenous differences between the two. This is why it is interesting to compare the two forms of provision allowing for differences in $\sigma_{P}$ and $\sigma_{G}$.
} 


\section{Asymmetric Information and the Selection Effect of Prices}

This section enriches the benchmark model introducing an asymmetry of information between the Government and the manager. The purpose is to investigate how the choice on the form of provision is affected.

From now on assume that only the manager knows the actual value of its cost reducing efficiency $\sigma$. Let $\sigma_{P}^{2}$ and $\sigma_{G}^{2}$ be two independent random variables uniformly distributed in $[0,1]$. Therefore, the expected efficiencies of the private and the public manager are ex-ante identical. This assumption is motivated by the fact that it is reasonable to assume that there is some variance in the managers' efficiency, a variable not easily observable. If this is so, the introduction of the privatization mechanism could induce endogenous ex-post differences in the efficiencies of the private and public manager that have important welfare consequences and, therefore, should not be dismissed.

To illustrate this endogenous effect, we need to take a closer look at the contract on which private provision is based. Suppose that the Government sets a take-it-or-leaveit transfer $T$ which denotes the total amount of money paid by the private manager to become the service provider. Notice that in the story told so far the transfer is simply the privatization price, i.e. $T=P_{F}$, but later on, when corruption is introduced, $T$ could also include a bribe.

The private manager enters the contract only if $T$ is smaller than the profit that he can extract by providing the good, i.e. if:

$$
\sigma_{P} \sqrt{e}-e \geq T
$$

or, taking into account the private manager's optimal effort $e_{P}=\frac{\sigma_{P}^{2}}{4}$, if $\sigma_{P}^{2} \geq 4 T$. When this condition is satisfied, provision is private. If, instead, $T$ is too large, the good is provided by a public employee.

Therefore, social welfare, as a function of the private manager's efficiency, is given by:

$$
W= \begin{cases}W_{P}\left(\sigma_{P}^{2}\right) & \text { if } \sigma_{P}^{2} \geq 4 T \\ W_{G}\left(\sigma_{G}^{2}\right) & \text { if } \sigma_{P}^{2}<4 T\end{cases}
$$

This implies that the choice of the transfer $T$ has important consequences not only on the form of provision but also on the ex-post efficiency of the managers. In particular, the Government, by setting $T$, can indirectly make a (positive) selection on the type of private manager even if he cannot observe the value of $\sigma_{P}$ : since less efficient private managers are less willing to pay to get the facility, any strictly positive transfer will exclude less efficient managers (Buia and Molinari 2012).

To evaluate the welfare consequences of this selection effect, denote with $\bar{W}(T)$ the expected social welfare as a function of $T$. There are two cases to consider: if $T \leq \frac{1}{4}$, the service is provided by the Government for low values of the 
private manager's efficiency and privately otherwise. Therefore, the expected social welfare is:

$$
\begin{aligned}
\bar{W}(T) & =\int_{0}^{4 T} \int_{0}^{1} W_{G}\left(\sigma_{G}^{2}\right) d \sigma_{G}^{2} d \sigma_{P}+\int_{4 T}^{1} W_{P}\left(\sigma_{P}^{2}\right) d \sigma_{P}^{2} \\
& =W_{0}+\frac{1}{8}(1-\delta)-2 T^{2}(1-\delta)+\frac{\delta+3}{2(2+\delta)^{2}} T .
\end{aligned}
$$

If instead $T>\frac{1}{4}$, the contract is never accepted by the private manager and provision of the good is always public. In this case:

$$
\bar{W}(T)=\int_{0}^{1} W_{G}\left(\sigma_{G}^{2}\right) d \sigma_{G}^{2}=W_{0}+\frac{1}{8} \frac{\delta+3}{(2+\delta)^{2}} .
$$

We can now use the function $\bar{W}(T)$ to compute the first best decision of a benevolent planner, i.e. the transfer $T^{*}$ that maximize expected social welfare:

$$
T^{*}=\frac{\delta+3}{8(1-\delta)(2+\delta)^{2}} .
$$

As it turns out, the transfer $T^{*}$ is increasing in $\delta$ : the price paid by the private manager accounts for the social damages he produces as a result of cost cutting. In other words, a benevolent planner uses the transfer to operate a selection on the manager's capacity to reduce cost that is more severe when the adverse consequences of the reduction in costs are larger. By doing so, it makes privatization less likely for larger values of $\delta$ and, thus, eschews the undesirable over-incentive to innovate implicit in private provision. Given this transfer, in fact, privatization occurs only when

$$
\sigma_{P}^{2} \geq \frac{\delta+3}{2(1-\delta)(2+\delta)^{2}},
$$

and it never occurs when $\delta$ is greater than a threshold value $\overline{\bar{\delta}}=0.7523$.

As Eq. 3 reveals, this is the first best privatization decision (given that the expected value of the public employee's efficiency $\sigma_{G}$ is equal to $1 / 2$ ) conditional on the Government's lack of information on the cost reducing efficiencies $\sigma_{P}$ and $\sigma_{G}$.

\section{Institutions and the Second Best}

Using the framework developed so far, we want to investigate the second best properties of shortcomings in the quality of institutions. In particular, we introduce two possible distortions from the ideal situation of a benevolent planner: bad governance and corruption.

As motivated in the Introduction, we define bad governance in terms of the quality of information available to the decision makers. In particular, assume that exact information on the parameter $\delta$, measuring the social cost of the innovation, is accessible only at the lower level of the organization and that the transmission of such information to the upper departments, where the decision making responsibility lies, 
depends on the quality of the institutions. Formally, let $d \in[0,1]$ be the signal on $\delta$ that the decision maker gets. With bad governance $d \neq \delta .5$

Corruption, instead, is defined in terms of the decision maker's objective function: a corrupt decision maker only cares about the bribe $B$ he can pocket and wishes to maximize it, disregarding any social welfare consideration. When corruption is allowed, the transfer $T$ includes the price of the facility and, possibly, a bribe $B$; i.e. $T=P_{F}+B$. Notice that our notion of corruption only depends on the objective function of the decision maker and it is independent of the type of governance; in other words, unlike some of the literature, our model does not equate corruption and bad governance.

In what follows we compute the equilibrium values of the transfer $T$ under alternative scenarios on the quality of governance and the presence of corruption and we compare them to the first best benchmark transfer $T^{*}$. Notice that our ultimate intent is not to establish that a faulty institutional setting decreases welfare (a rather uninteresting result) but, instead, aims to expose the sources of such decline.

\section{The Role of Corruption}

We first consider the case of corruption and good governance. A corrupt Government only cares about the bribe he can pocket. Since privatization occurs only when $\sigma_{P}^{2}$ is greater than $4 T$, the expected illegal payment is given by

$$
\int_{4\left(B+P_{F}\right)}^{1} B d \sigma^{2}
$$

and it is maximized when the bribe is set at $B=\frac{1}{8}$ and $P_{F}=0$. Notice that the price of the facility is set to zero because any strictly positive amount would unnecessarily decrease the probability that the manager accepts the contract and pays the bribe.

In this case, then, even if the Government knows the social cost $\delta$ because governance is good, it does not care about social welfare due to corruption and, therefore, it ignores his information and asks for a fixed transfer. This implies that the type of governance is inconsequential when there is corruption because a dishonest decision maker is not going to use his information on $\delta$. Therefore, equilibrium transfer and social welfare are going to be the same, regardless of the quality of institutions and we can label them by $c$.

Proposition 1 Corruption decreases expected social welfare with respect to the benevolent planner benchmark because the selection operated through the bribe is independent of the social cost of innovations.

\footnotetext{
${ }^{5}$ The alternative of having a noisy signal on $\delta$, although more natural from a decision-theoretical point of view, adds no further insights on the question at hand.
} 
Proof Since $T^{c}=\frac{1}{8}$, it is enough to show that $\bar{W}\left(T^{*}\right) \geq \bar{W}\left(\frac{1}{8}\right)$ for any value of $\delta$. Consider two cases:

1. for $\delta \geq \overline{\bar{\delta}}, T^{*} \geq \frac{1}{4}$ and

$$
\bar{W}\left(T^{*}\right)=W_{0}+\frac{1}{8} \frac{\delta+3}{(2+\delta)^{2}}>\bar{W}\left(\frac{1}{8}\right) ;
$$

2. for $\delta<\overline{\bar{\delta}}, T^{*}<\frac{1}{4}$ and $\bar{W}(T)$ is strictly increasing for $T<T^{*}$ and decreasing otherwise. Therefore $\bar{W}(T)$ reaches its overall maximum in $T=T^{*}$.

We want to stress that the result of Proposition 1 should not be dismissed as self-evident. Unlike most of the literature, in this model there is no exogenous distortionary effect of corruption; the allocation of the asset only depends on total transfer and, therefore, it is the same as long as the bribe chosen by a corrupt Government and the privatization price set by an honest public official are of equal value. This being so, any difference in welfare is endogenously determined and it is based on the different selection operated by a corrupt Government as opposed to a benevolent planner.

The intuition behind Proposition 1 is the following: the bribe, as any other monetary transfer, enacts a positive selection on the cost reducing efficiency of the private manager. In fact, given $T^{c}=\frac{1}{8}$, for $\sigma_{P}^{2}<\frac{1}{2}$, the private manager refuses to pay it and provision is public; when instead $\sigma_{P}^{2} \geq \frac{1}{2}$, the bribe is paid and the service is contracted out. Thus, only the $50 \%$ more efficient private managers pay the bribe. However, the selection operated by the bribe screens out private managers who get low benefits from implementing cost reductions, regardless of the social cost of privatizing (as measured by $\delta$ ). This is not the first best selection that a benevolent planner would enact and, therefore, it leads to a lower social welfare with respect to the first best benchmark.

\section{The Role of Bad Governance}

We now turn to analyze the equilibrium transfer when governance is bad and there is no corruption. In this case, that we label with $b$, the bribe is set to $B^{b}=0$ and $P_{F}^{b}$ is chosen to maximize social welfare. However, due to bad governance, the Government is badly informed on the social cost of the innovation and this leads to the choice of a less than optimal price for the facility. More precisely, using Eq. 4 and allowing for the Government (wrong) information $d \neq \delta$, we conclude that the price will be set to

$$
T^{b}=P_{F}^{b}=\frac{d+3}{8(1-d)(2+d)^{2}} .
$$


If, instead, bad governance is accompanied by corruption, the result is the one illustrated in the previous section.

Proposition 2 Bad governance decreases expected social welfare with respect to the benevolent planner benchmark.

Proof If there is corruption the results follows form Proposition 1. Without corruption the result follows straightforwardly from the definition of $T^{*}$ and the fact that $d \neq \delta$.

The source of the adverse effect on welfare lies, as before, in the fact that the Government enacts a "wrong" selection of the private managers' abilities. In particular, with corruption everything we said in the previous section applies. Without corruption, instead, the Government does try to take the social cost of the innovation into account when setting the transfer; however, due to bad governance, it lacks the information to set the right price. Either way, the selection among the private managers is not appropriate and the welfare is lower than in the social optimum. Obviously, in case the Government is honest, the magnitude of this adverse effect depends on the quality of the information received. If the signal $d$ is not far away from the true value of $\delta$, welfare will not be much lower than the one obtained in the first best benchmark; however, as the quality of the signal $d$ declines, so does the value of the expected welfare.

\section{A Second Best Theory of Institutional Quality and its Policy Implications}

We now consider a situation in which both corruption and bad governance are present to investigate how the removal of any one of them affects social welfare.

First we consider the removal of bad governance. This case is straightforward because we showed that a corrupt Government makes no use of its information. Therefore, when removing bad governance, social welfare is unchanged in spite of the additional information obtained.

The second situation, instead, involves the removal of corruption and leads to the comparison of a scenario with both corruption and bad governance with a situation where the only institutional shortcoming is bad governance. Given the results of the previous section, this require to compare $\bar{W}\left(T^{c}\right)$ and $\bar{W}\left(T^{b}\right)$, as we do in the next proposition.

Proposition 3 Under bad governance, for any $\delta$ there are values of the signal $d$ such that expected social welfare is lower when corruption is removed.

Proof Notice that the transfer $T^{b}$ is a continuous variable of $d$ and it takes any value greater than $\frac{3}{32}$ as $d$ ranges in [0,1]. Therefore, for any value of $\delta$ it is enough to find values of the transfer $T \geq \frac{3}{32}$ such that $\bar{W}(T)<\bar{W}\left(\frac{1}{8}\right)$. 
The function $\bar{W}(T)$ is a concave parabola for $T \leq \frac{1}{4}$ and a constant horizontal line for $T \geq \frac{1}{4}$; it has a maximum in $T^{*}$ if $\delta \leq \overline{\bar{\delta}}$ and a continuum of maxima for $T \geq \frac{1}{4}$ otherwise. Also, $T^{*}$ is increasing in $\delta$ and is equal to $\frac{1}{8}$ when $\delta=\bar{\delta}$. Consider two cases:

(i) if $\delta \geq \bar{\delta}$ then $T^{*} \geq \frac{1}{8}$ and $\bar{W}(T)$ is strictly increasing on the interval $\left[0, \frac{1}{8}\right]$. Therefore any $T \in\left[\frac{3}{32}, \frac{1}{8}\right)$ leads to an expected social welfare lower than the one obtained with corruption.

(ii) if $\delta<\bar{\delta}$ then $T^{*} \leq \frac{1}{8}$ and $\bar{W}(T)$ is strictly decreasing on the interval $\left[\frac{1}{8}, \frac{1}{4}\right]$ and constant for $T \geq \frac{1}{4}$. Therefore any $T>\frac{1}{8}$ leads to an expected social welfare lower than the one obtained with corruption.

The intuition of the result of Proposition 3 lies in the type of selection operated in each institutional environment: under bad governance an honest but uninformed decision maker, trying to set a privatization price that takes into account the social cost of the reduced quality associated to lower cost, could make a worse selection of the manager's efficiency than a corrupt decision maker; the latter, in fact, does not care about social welfare but nevertheless makes some positive selection on private managers because the more efficient are also the ones capable to pay a higher bribe.

Overall, our model shows that the removal of only one imperfection of the institutional quality may affect welfare either by raising it, by lowering it, or by leaving it unchanged. Therefore, there is no a priori easy way to compare situations which are closer to the first-best on some dimensions but not on others.

By extending the theory of the second best to the case of institutional constraints, our result also extends its policy implications. One of Lispey and Lancaster's main message is that when there are distortions in a sector of the economy, it may not be optimal to have the usual first-best efficiency conditions satisfied in the remaining, non-distorted, sectors of the economy. In other words, moving away from some conditions of optimality may not be inefficient if other constraints to optimality are already in place. This implies that in a second best world, policy prescriptions cannot be easily formulated because they cannot be based on simple first-best recommendations.

When this finding is translated to our institutional setting, we come to the conclusion that a piecemeal approach that attempts to remove an institutional imperfection whenever possible will not necessarily be optimal. Then, if the Government is unable to remove all the distortions at once, it is not clear which path it should take in trying to move to the first best world of good-governance-and-no-corruption, In fact, the mere removal of corruption might not be beneficial if it is not accompanied by other institutional improvements because it might have undesirable consequences on the selection of managers operated in equilibrium. 


\section{Conclusion}

This paper extends the theory of the second best from market to institutional constraints. Using a model of the trade-off, in terms of cost and quality, of public or private supply of a service, we introduce corruption and bad governance as possible faults in the institutions governing the decision to privatize. The reason we choose this setting is because privatization is notoriously a field where corruption thrives.

We show that any institutional scenario leads to a distinct privatization price and, therefore, to a different selection of the private manager's efficiency. We use these diverse selection effects to prove that the existence of an institutional failure (bad governance) does not make the removal of a second institutional failure (corruption) necessarily desirable. The important insight is that even a corrupt Government performs a positive selection of the manager's efficiency, not for social welfare reasons but because the more efficient managers can pay a higher bribe. This selection is not as appropriate as the one obtained in the ideal situation of an honest and well informed decision-maker, but it could be better that the one realized by an honest Government that is poorly informed.

This result illustrates one of the mechanisms through which corruption could counteract other institutional shortcomings and, thus, offers an explanation of some of the puzzles in the recent empirical literature.

Acknowledgments I wish to thank M. LiCalzi and R. E. Buia for helpful comments.

\section{References}

Aidt, T. (2003). Economic analysis of corruption: a survey. The Economic Journal, 113(491), F632-F652.

Aidt, T., Dutta, J., Sena, V. (2008). Governance regimes, corruption and growth: theory and evidence. Journal of Comparative Economics, 36(2), 195-220.

Bardhan, P. (1997). Corruption and development: a review of issues. Journal of Economic Literature, 35(3), 1320-1346.

Beck, P.J., \& Maher, M.W. (1986). A comparison of bribery and bidding in thin markets. Economics Letters, 20(1), 1-5.

Blackburn, K., \& Forgues-Puccio, G.F. (2009). Why is corruption less harmful in some countries than in others? Journal of Economic Behavior \& Organization, 72(3), 797-810.

Boadway, R. (1997). The role of second-best theory in public economics. In B.C. Eaton, \& R.G. Harris (Eds.), Trade, technology and economics essays in honour of Richard G. Lipsey (pp. 3-25). Cheltenham: Edward Elgar.

Buia, R.E., \& Molinari, M.C. (2012). Corruption and positive selection in privatization. Research in Economics, 66(4), 297-304.

de Vaal, A., \& Ebben, W. (2011). Institutions and the relation between corruption and economic growth. Review of Development Economics, 15(1), 108-123.

Ehrlich, I., \& Lui, F.T. (1999). Bureaucratic corruption and endogenous economic growth. Journal of Political Economy, 107(S6), S270-S293.

Hart, O., Shleifer, A., Vishny, R.W. (1997). The proper scope of government: theory and an application to prisons. The Quarterly Journal of Economics, 112(4), 1127-1161.

Heckelman, J.C., \& Powell, B. (2010). Corruption and the institutional environment for growth. Comparative Economic Studies, 52(3), 351-378.

Laffont, J.-J. (1988). Fundamentals of public economics. Cambridge: The MIT Press.

Li, S., \& Wu, J. (2010). Why some countries thrive despite corruption: the role of trust in the corruptionefficiency relationship. Review of International Political Economy, 17(1), 129-154. 
Lui, F.T. (1985). An equilibrium queuing model of bribery. Journal of Political Economy, 93(4), 760-781.

Lipsey, R.G. (2007). Reflections on the general theory of second best at its golden jubilee. International Tax and Public Finance, 14(4), 349-364.

Lipsey, R.G., \& Lancaster, K. (1956). The general theory of second best. The Review of Economic Studies, 24(1), 11-32.

Méndez, F., \& Sepùlveda, F. (2006). Corruption, growth and political regimes: cross country evidence. European Journal of Political Economy, 22(1), 82-98.

Mèon, P.G., \& Sekkat, K. (2005). Does corruption grease or sand the wheels of growth? Public Choice, 122(1-2), 69-97.

Mèon, P.G., \& Weill, L. (2010). Is corruption an efficient grease? World Development, 38(3), 244-259.

Rock, M.T., \& Bonnett, H. (2004). The comparative politics of corruption: accounting for the East Asian paradox in empirical studies of corruption, growth and investment. World Development, 32(6), 9991017.

Svensson, J. (2005). Eight questions about corruption. The Journal of Economic Perspectives, 19(3), 1942.

Vial, V., \& Hanoteau, J. (2010). Corruption, manufacturing plant growth, and the Asian paradox: Indonesian evidence. World Development, 38(5), 693-705.

M. Cristina Molinari is Assistant Professor at the Department of Economics, University Ca' Foscari Venezia, Italy. 